Original Research Paper

\title{
Examination of Laminated Glass with Stiff Interlayers - Numerical and Experimental Research
}

\author{
${ }^{1}$ Julian Hänig, ${ }^{1}$ Paulina Bukieda, ${ }^{2}$ Michael Engelmann, ${ }^{3}$ Ingo Stelzer and ${ }^{1}$ Bernhard Weller \\ ${ }^{I}$ TU Dresden, Institute of Building Construction, Dresden, Germany \\ ${ }^{2}$ Josef Gartner GmbH, Gundelfingen, Germany \\ ${ }^{3}$ Kuraray Europe GmbH - PVB Division, Hattersheim, Germany
}

Article history

Received: 26-09-2018

Revised: $12-12-2018$

Accepted: 22-01-2019

Corresponding Author: Julian Hänig

TU Dresden, Institute of Building Construction,

Dresden, Germany

Email: Julian.haenig@tu-dresden.de

\begin{abstract}
Glass is a linear-elastic and isotropic building material which allows for a quick calculation of internal forces and stress in the design stage. However, in safety applications, e.g. overhead glazing or balustrades, it is made into laminated glass using plastic interlayers. Their material properties change over time and are temperature-dependent. Additionally, larger spans and the demand to reduce the amount of material used to a minimum result in significant slenderness and a considerable impact of geometric non-linearity. Consequently, the manufacturing of laminated glass products results in the requirement of complex design strategies to generate top performance. The paper introduces current design methods for laminated glass focusing on the potential use of shear action and covering load assumptions, including the effects of time and temperature. It includes a study on potential material models for three different interlayers. This led to a refined numerical model for load combinations considering shear action. For validation, vertical laminated glass panels (linearly supported on four sides) were loaded. The 36 specimens comprised two sizes: one measured $800 \mathrm{~mm}$ by $1200 \mathrm{~mm}$ and the other $1450 \mathrm{~mm}$ by $2800 \mathrm{~mm}$ and layers of glass with a thickness ranging from $3 \mathrm{~mm}$ to $4 \mathrm{~mm}$. A planar load was introduced stepwise according to a load-time correlation model. Time and deflection correlate as a function of the interlayer. The idea was to quantify the performance of standard-PVB, stiff PVB and ionoplast interlayers as well as a monolithic glass pane as reference. The results show good agreement in comparison with the refined numerical calculations. Therefore, the load-bearing behaviour of laminated glass can be realistically modelled and allows for an economic glass design. Additionally, the numerical model was applied in an extended parametric study on the possible reduction of self-weight by using a combination of thin glass panes and stiff interlayers in insulated glass units. A resulting "butterfly chart" shows the potential of self-weight reduction as a broader summary.
\end{abstract}

Keywords: laminated Glass, Stiff Interlayers, Numerical Research, Shear Action, Experimental Research, Refined Calculation Method

\section{Introduction}

Architects and engineers wish to enlarge the spans of glazings and increase transparency by using slender structures. However, large glazings need enhanced stiffness to ensure a sufficient load-bearing capacity. This is usually realised with thicker glass structures. Consequently, the increasing self-weight of the glazings is a decisive factor in designing the substructure. Furthermore, in modernisations the self-weight and the thickness of the glazings are often limited to reuse the existent substructure (Brenne et al., 2014). Due to energy savings, new glazings have to be insulated glass units with higher self-weight in general.

Hence, the manufacturing of laminated glass products results in the requirement of self-weight reduction and thin structures. The combination of structural properties of the interlayer with refined calculation methods enables the design of high-performance lightweight laminated glass. 
The mechanical material properties, such as stiffness, strength and creep of polymeric interlayers, change according to the temperature (ranging from $20^{\circ} \mathrm{C}$ to $+60^{\circ} \mathrm{C}$ ) (prEN 16613, 2017b). Moreover, the load conditions have a significant influence on the material behaviour. A standard polymer PVB interlayer has a glass transition temperature between $15^{\circ} \mathrm{C}$ to $20^{\circ} \mathrm{C}$ (Juang et al., 2001). Consequently, the glass transition temperature of standard-PVB is transcended regularly. In the thermoplastic state, the interlayer cannot carry shear forces any more. Interlayers such as a stiff PVB (Trosifol ${ }^{\circledR}$ Extra Stiff) or ionoplast (SentryGlas ${ }^{\circledR}$ ) exhibit higher glass transition temperatures of up to $50^{\circ} \mathrm{C}$ (Kuntsche et al., 2015) due to improved chemical compositions. This leads to a significant coupling between the glass panes during a larger range of temperature. This effect of coupling is schematically described in Fig. 1 by stress distribution comparison between no shear coupling, partial shear coupling and full shear coupling in a laminated glass cross section. Due to coupling effects, the maximum stresses can be highly reduced. The stresses converge to monolithic behavior depending on the stiffness of the interlayer.

Currently, the design of laminated glass is regulated in national glass standards as discussed in (Kraus et al., 2018). The design according to the German standard (DIN 18008) is conservative and advantageous shear coupling between glass panes under static loads cannot be taken into account for the calculation of stresses and deflections. Additional approvals are necessary to verify the use of shear stiffness. In those approvals, valid for Germany, elastic shear moduli for individual applications and load cases are given (Z-70.3-236; Z70.3-170). However, the most finite-element programmes as well as calculation methods (e.g. prEN 16612) do not allow full geometric non-linear calculations by adapting the shear modulus in load combinations. As a result, the load-bearing behaviour in load combinations and its dependence on the load duration and temperature are modelled only to a limited degree. Furthermore, in load combinations geometric non-linear effects such as the membrane effect in plates that are linearly supported on four sides are not considered in their entirety. This might lead to uneconomic laminated glass design. The complexity in calculations of laminated glass lies in the calculation method itself as well as in the assumptions of interlayer properties.

This article presents a refined calculation method for modelling realistic load-bearing behaviour of laminated glass. It integrates stiffness that is dependent on both time and temperature and allows for a geometric nonlinear calculation of load combinations. This leads to a more economic design of laminated glass panes and hence, to potential larger laminated glass design and reduced self-weight compared to conventional calculation methods. Hence, an additional comparison with conventional calculation methods is provided.

To validate the model and to quantify the performance of stiff interlayers, the Institute of Building Construction at the TU Dresden together with Kuraray Europe $\mathrm{GmbH}$ evaluated the load-bearing behaviour of laminated glass with different interlayers during a fullscale experimental investigation in a façade test rig. The specimens comprised two representative dimensions of $800 \mathrm{~mm}$ by $1200 \mathrm{~mm}$ (window-sized glazing) and 1450 $\mathrm{mm}$ by $2800 \mathrm{~mm}$ (ceiling-high glazing) with glass thicknesses of $3 \mathrm{~mm}$ and $4 \mathrm{~mm}$. A planar load was introduced stepwise according to a load-time correlation model for wind loads (Haldimann, 2008). This results in the correlation between time and deflection as a function of the interlayer. The idea was to quantify the performance of standard-PVB, stiff PVB and ionoplast interlayers as well as a monolithic glass pane as reference.

Finally, a parametric study with the refined numerical model was conducted to visualise the performance using the shear stiffness of the interlayer (s). As a broader summary, a "butterfly chart" shows the potential of self-weight reduction in large insulated glass units.

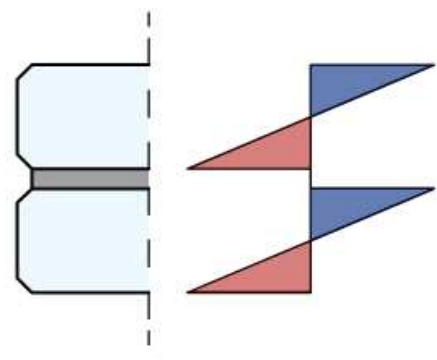

No shear coupling

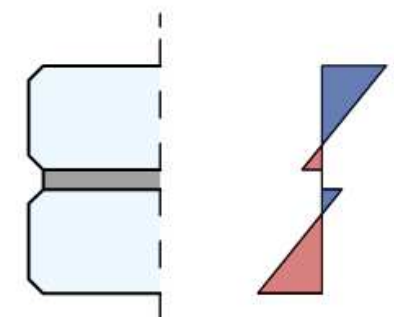

Partial shear coupling

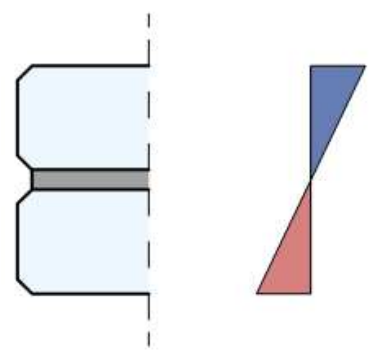

Full shear coupling

Fig. 1: Comparison of stress distribution due to coupling effects in laminated glass (schematic illustration) 


\section{Materials and Methods}

\section{Shear Coupling in Finite-Element Models}

According to the German glass standard no advantageous shear action is allowed to be taken into account (DIN 18008). However, additional general technical approvals permit the consideration of shear stiffness in calculations. The elastic shear modulus values for different applications and load cases are given (Z-70.3-236; Z-70.3-170). An excerpt of those values is reproduced in Table 1 for different interlayers.

Hence, the stresses and deflections with flexible bond between the glass panes can be determined analytically using formulas, e.g. provided in (Galuppi and RoyerCarfagni, 2012a; López-Aenlle et al., 2013; PrEN 16612, 2017a), or numerically using finite-element programmes and considering the corresponding shear stiffness.

The elastic shear modulus values $G$ in the general technical approvals originate from Dynamic Mechanical Thermal Analysis DMTA on interlayer material properties. Additionally, the values were verified and adjusted by performing four-point bending tests with different load durations and temperatures similar to (Serafinavičius et al., 2013).

Describing the shear stiffness of the interlayer(s), Prony-series combined with time-temperature shifting (Pelayo et al., 2017; Hanak et al., 2017) as well as functions that are dependent on time and temperature, or tables based on material investigations (Van Duser et al., 1999; Bennison et al., 2001; 2008; KDT, 2016) can be used alternatively. To give an overview, shear modulus values G out of DMTA are compared in Table 2.

Table 1: Selected elastic shear moduli of different interlayers according to DIN 18008 and general technical approvals Elastic shear modulus $G\left[\mathrm{~N} / \mathrm{mm}^{2}\right]$

\begin{tabular}{|c|c|c|c|}
\hline \multirow[b]{2}{*}{ Load case } & \multicolumn{3}{|c|}{ Elastic shear modulus $G\left[\mathrm{~N} / \mathrm{mm}^{2}\right]$} \\
\hline & $\begin{array}{l}\text { standard-PVB } \\
\text { Trosifol® Clear }\end{array}$ & $\begin{array}{l}\text { stiff PVB Trosifol }{ }^{\circledR} \\
\text { Extra Stiff }\end{array}$ & $\begin{array}{l}\text { ionoplast } \\
\text { Sentry Glas }{ }^{\circledR}\end{array}$ \\
\hline $\begin{array}{l}\text { Dead load } \\
\text { (permanent load) }\end{array}$ & $\begin{array}{l}\text { no shear } \\
\text { coupling }\end{array}$ & $\begin{array}{l}\text { no shear } \\
\text { coupling }\end{array}$ & $\begin{array}{l}\text { no shear } \\
\text { coupling }\end{array}$ \\
\hline $\begin{array}{l}\text { Snow load } \\
\left(30 \text { days } @ 0^{\circ} \mathrm{C}\right)\end{array}$ & $\begin{array}{l}\text { no shear } \\
\text { coupling }\end{array}$ & 100 & 60 \\
\hline $\begin{array}{l}\text { Wind load } \\
\text { (short impact) }\end{array}$ & $\begin{array}{l}\text { no shear } \\
\text { coupling }\end{array}$ & 7 & 100 \\
\hline
\end{tabular}

Table 2: Selected elastic shear modulus values $G$ for different load duration times and temperatures (KDT, 2016)

\begin{tabular}{|c|c|c|c|}
\hline \multirow[b]{2}{*}{$\begin{array}{l}\text { duration time } t \\
\text { (a) Temp. } T\end{array}$} & \multicolumn{3}{|c|}{ Elastic shear modulus $G(t, T)\left[\mathrm{N} / \mathrm{mm}^{2}\right]$} \\
\hline & $\begin{array}{l}\text { Trosifol }{ }^{\circledR} \\
\text { Clear }\end{array}$ & $\begin{array}{l}\text { Trosifol }{ }^{\circledR} \\
\text { Extra Stiff }\end{array}$ & SentryGlas ${ }^{\circledR}$ \\
\hline 1 year $@ 20^{\circ} \mathrm{C}$ & 0.03 & 1.6 & 96.5 \\
\hline 1 month @ $20^{\circ} \mathrm{C}$ & 0.4 & 1.9 & 112 \\
\hline 1 minute@20ㄷ & 1.6 & 196 & 195 \\
\hline 3 seconds $@ 20^{\circ} \mathrm{C}$ & 8 & 342 & 211 \\
\hline
\end{tabular}

The values provided for stiff interlayers (Trosifol® Extra Stiff and SentryGlas ${ }^{\circledR}$ ) are significantly higher compared to values provided for standard-PVB (Trosifol ${ }^{\circledR}$ Clear). However, for Germany, just the approval values of Table 1 are allowed to be considered in calculations.

Figure 2 describes the influence of the shear modulus $G$ on maximum glass stresses and laminated glass deflections examined numerically with the commercial finite-element programme RFEM 5.07 (Dlubal Software $\mathrm{GmbH}, 2016)$. This is presented for the particular case shown in Fig. 2 (modelled with linear supports, solid elements, mesh: $30 \mathrm{~mm}$, non-linear analysis - Newton Raphson) under a planar load of $1 \mathrm{kN} / \mathrm{m}^{2}$ and $2 \mathrm{kN} / \mathrm{m}^{2}$. The effects, maximum glass stress $\sigma$ and deflection $u$, are described by means of the ratio between shear coupling and no shear coupling of the glass panes. It shows that applying a shear modulus $G$ of $10 \mathrm{~N} / \mathrm{mm}^{2}$ in calculations is sufficient to lead to a nearly $(7 \%$ variance) full shear coupling. In this case, the stresses can be reduced to around $50 \%$ and the deflections to around $25 \%$. Consequently, considering shear coupling leads to an economic laminated glass design.

\section{Conventional Calculation}

In plates that are linearly supported on four sides, favourable operating membrane effects arise. These effects are just considered by using geometric non-linear calculations. Figure 3 schematically illustrates the differences between geometric linear (characteristic impact/loading $\left.E_{\text {char }}\right)$ and geometric non-linear calculation (design impact/loading $E_{d}$ - using safety factors $\gamma$ ). The chart shows the effects (stresses $\sigma$ and deflections $u$ ) by means of the impact assumed as uniformly distributed load. The effects increase less for geometric non-linear calculations compared to linear ones due to membrane effects depending on the level of impact/loading. Therefore, linear calculation leads to significant higher stresses $\sigma$ and deflections $u$ due to not considering membrane effects.

Currently, the superposition principle (summation of stresses and deflections) for load combinations is used for glass designs in ultimate limit state ULS and serviceability limit state SLS. Table 3 describes the calculation method procedure by using combination and safety factors $\Psi$ and $\gamma$ according to the regulations of Eurocode (DIN EN 1990).

According to the chart in Fig. 3 and the procedure shown in Table 3, using geometric non-linear calculations reduces the effects (stresses and deflections) due to favourable operating membrane effects. For a full geometric non-linear calculation of load combinations, the combined impacts/loadings should be used to achieve a precise and economic glass design.

However, each load is influenced by a specific duration and temperature in any given situation. This leads to a specific shear modulus for each load. 


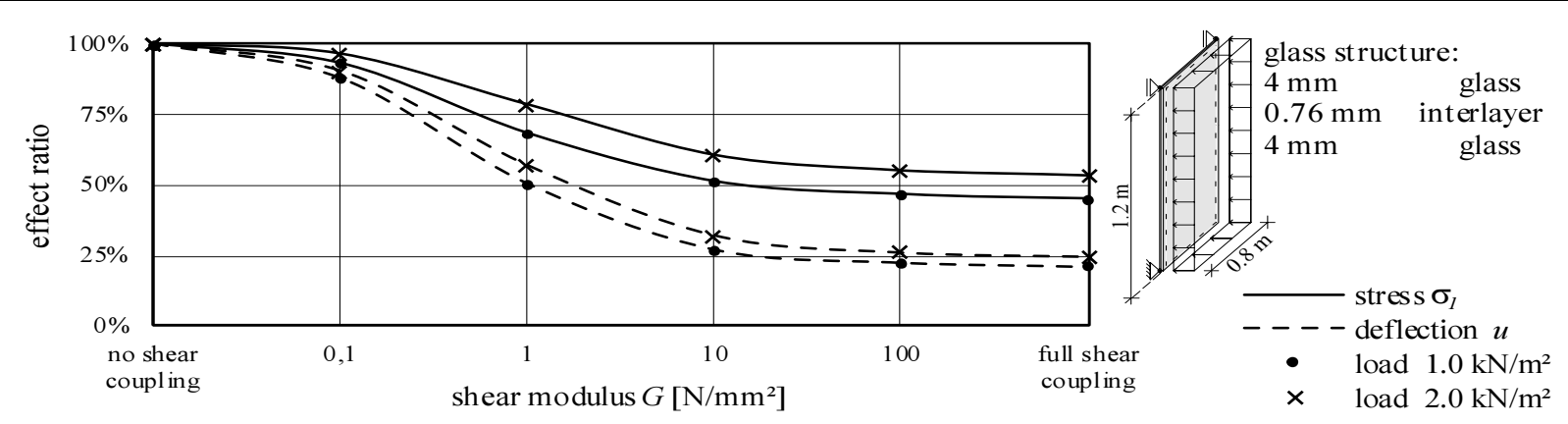

Fig. 2: Influence of shear modulus (stress ratio $\sigma_{\text {shear }}$ coupling/ $\sigma_{\text {no shear }}$ coupling and deflection ratio $u_{\text {shear coupling }} / u_{\text {no shear coupling }}$ )

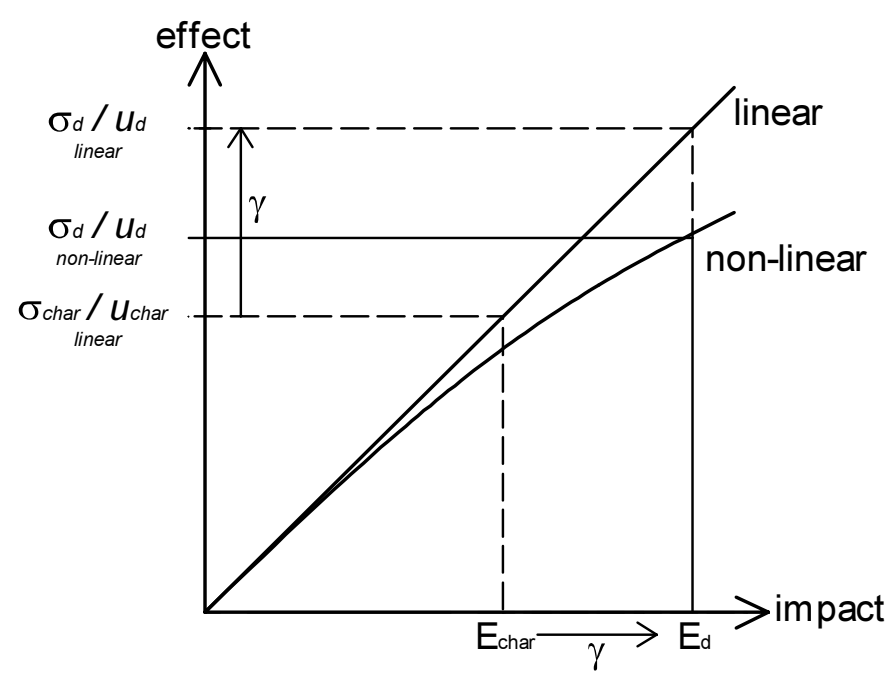

Fig. 3: Linear and non-linear impact-effect chart for linearly supported plates on four sides (schematic illustration)

Table 3: Superposition principle for geometric linear and non-linear calculations

\begin{tabular}{|c|c|c|}
\hline load case & geometric linear & geometric non-linear \\
\hline \multirow[t]{2}{*}{ Dead load $d$} & 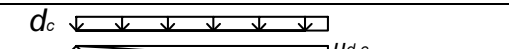 & 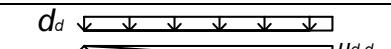 \\
\hline & hm $\quad \sigma d, c \leftrightarrow 4 d, c$ & $\widehat{\mathrm{m} n} \quad \sigma d, d \leftrightarrow$ \\
\hline \multirow[t]{2}{*}{ Snow load $s$} & Sc $\downarrow \begin{array}{llllll} & \downarrow & \downarrow & \downarrow & \downarrow & \downarrow\end{array}$ & 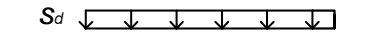 \\
\hline & भाग $\quad \sigma_{s, c} \leftrightarrow U s, c$ & $\sigma_{s, d \leftrightarrow} \leftrightarrow u_{s, d}$ \\
\hline \multirow[t]{2}{*}{ Wind load $w$} & 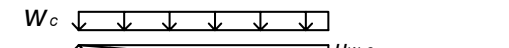 & 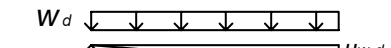 \\
\hline & Aाग $\quad \sigma_{w, c \leftrightarrow} \leftrightarrow u_{w, c}$ & $\sigma_{w, d \leftrightarrow} u_{w, d}$ \\
\hline $\begin{array}{l}\text { ULS } \\
\text { SI S }\end{array}$ & $E_{d}=\gamma_{G} \cdot \sigma_{d, c}+\gamma_{O} \cdot \sigma_{s, c}+\gamma_{O} \bullet \gamma_{0} \cdot \sigma_{w, c}$ & $E_{d}=\sigma_{d, d}+\sigma_{s, d}+\sigma_{w, d}$ \\
\hline SLS & $E_{d}=u_{d, c}+u_{s, c}+\Psi_{0} \cdot u_{w, \mathrm{c}}$ & $E_{d}=u_{d, d}+u_{s, d}+u_{w, d}$ \\
\hline
\end{tabular}

Most calculation methods as well as finite-element programmes do not offer the possibility to adapt the shear modulus for each load in load combinations. Hence, the effects are determined separately for each load and summed up in the end to get the resulting stresses or deflections (superposition principle as shown in Table 3). This leads to a limited modelling of the loadbearing behaviour, dependent on load and temperature. The following chapter presents a refined geometric nonlinear calculation method for modelling the realistic loadbearing behaviour of laminated glass by considering the precise shear stiffness under combined loads.

\section{Refined Calculation Method}

The aim of the refined calculation method (first presented in (Hänig et al., 2018)) is a geometric nonlinear model for capturing the realistic load-bearing behaviour of laminated glass.

The difference between linear and non-linear calculations lies in the equation solving. For non-linear calculations the solution is found by iteration, whereas linear calculations solve the equations in one single step. As consequence non-linear calculations consider the previous deformation and recalculate the new stiffness of the body. 
This leads to an enhanced stiffness in plates that are supported on four sides by taking membrane effects into consideration in the deformed state.

For the refined calculation method in particular, the geometric non-linear correlation between the stress and deflection of predefined loads is considered. Consequently, the combined load and the elastic shear moduli, dependent on both time $t$ and temperature $T$, are applied to each load as a constant value $G(t, T)$. The strategy for combining loads and considering the shear moduli is realised with an approach of pre-deformation.

Table 4 shows the principle for the refined calculation method in a single span beam. The deformations and stresses under load $p_{1}$ from the first load step with the related shear modulus $G_{1}$ are transferred to the next load step by applying predeformation. This introduces the stresses and deformations into the system. The next load step is calculated with the adjusted shear modulus $G_{2}$. The same procedure is used for the last step: pre-deformation is applied and the resulting stresses and deflections are determined with the aid of the shear modulus $G_{3}$. After the last load step, all shear modulus values for the corresponding load are included in the final stress and deflection state. In the refined calculation method the exact load history - long load durations before short duration - has to be respected.

All in all, the elastic shear modulus value $G$ can be applied separately to each load according to Table 1 or from time $t$ and temperature $T$ correlations (e.g. Bennison et al., 2001). In summary, this method provides an accurate quasi-static geometric non-linear calculation of load combinations by considering time and temperature dependent material behaviour of the interlayer.

For implementing the refined method in a numerical model, the finite-element programme RFEM 5.07 was used. The glass structure was assumed by multi-layered solid shell elements for all layers with a mesh of $30 \mathrm{~mm}$. All four edges of the glazing were linearly supported. For adapting the shear modulus in each load, the approach of pre-deformation was implemented according to Table 4. The Newton-Raphson method was used to make geometric non-linear calculations. The support conditions and element size are summarised in Fig. 4.

Table 4: Approach of pre-deformation for combining loads

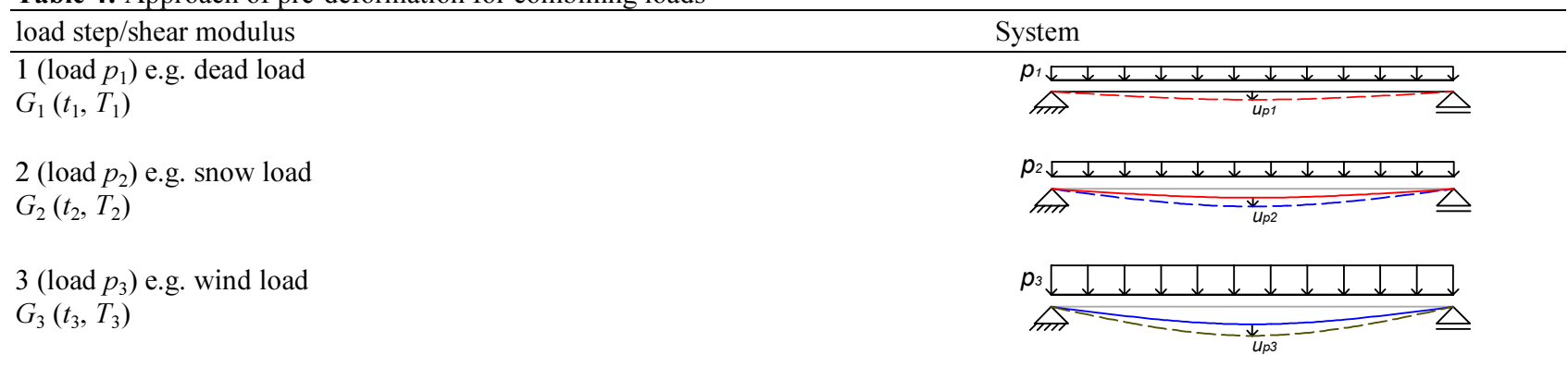

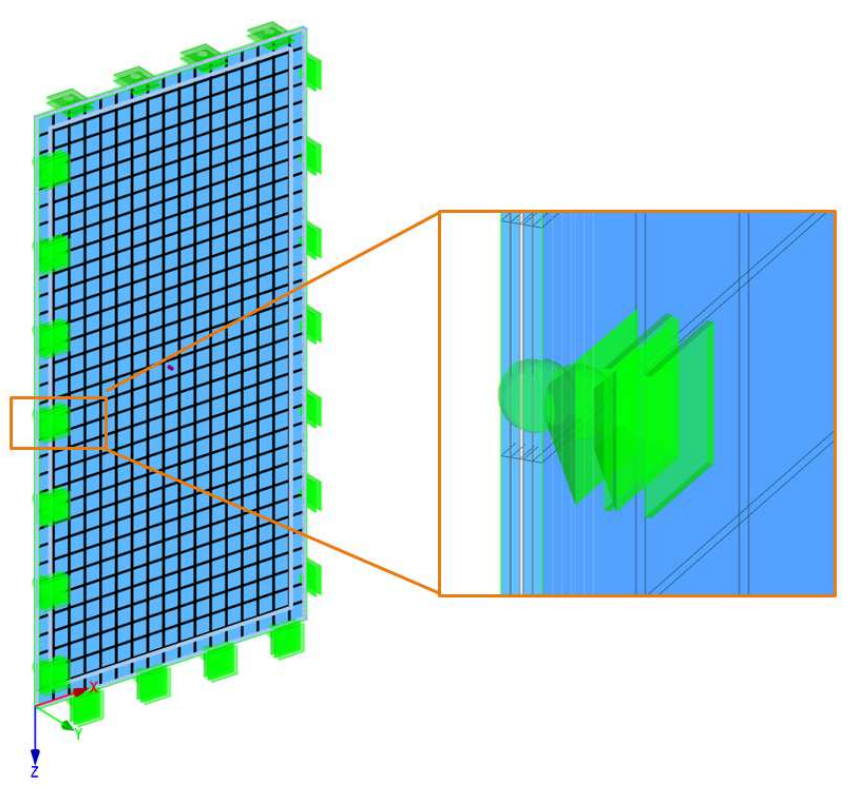

Fig. 4: Finite-element quarter model (symmetry used) with support detail and element size 
Table 5: Calculation method comparison (44.2 laminated glass, loads: $p_{1}=0.5 \mathrm{kN} / \mathrm{m}^{2}$ and $p_{2}=1.0 \mathrm{kN} / \mathrm{m}^{2}$ )

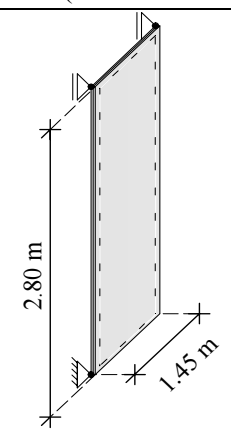

\begin{tabular}{llll} 
& Calculation & Max stress $\sigma_{1}$ & $\begin{array}{l}\text { Max middle } \\
\text { deflection } u[\mathrm{~mm}]\end{array}$ \\
\hline No shear coupling & geometric linear & 59.52 & 81.05 \\
& geometric non-linear & 23.70 & 26.90 \\
Shear coupling & geometric linear & 25.39 & 16.62 \\
$G_{1}=7 \mathrm{~N} / \mathrm{mm}^{2}$ & geometric non-linear & 23.77 & 15.59 \\
$G_{2}=100 \mathrm{~N} / \mathrm{mm}^{2}$ & refined method & 15.00 & 14.09 \\
\hline
\end{tabular}

To show the differences between several calculation methods, the resulting maximum stresses and deflections in a laminated glass pane which is linearly supported on four sides and under two planar loads are compared with one another in Table 5. All calculations were performed numerically with the finite-element programme RFEM. The deformations without shear coupling are significantly higher than the ones considering shear coupling. Additionally, the geometric linear calculation leads to higher stresses and deflections due to not considering membrane effects. Both calculation methods result in an overestimation of stresses and deformations.

Nevertheless, with the full geometric non-linear calculation (refined method) using the approach of predeformation and applying the load-dependent shear moduli, the stresses and deflections are below those yielded with conventional methods.

Consequently, the refined calculation method reaches an economic laminated glass design by applying the precise shear modulus to each load by using the approach of pre-deformation. For validation of the refined calculation method, a full-scale experimental investigation was performed. The following chapter discusses the procedure and the results.

\section{Experimental Investigation}

\section{Introduction and Specimens}

The two objectives of the experimental investigation in a façade test rig were the validation of the refined calculation method and the validation of the shear moduli of the interlayer (s) for the subsequent numerical study.
Table 6: Specimen glass structure for window-sized glazing and ceiling-high glazing

\begin{tabular}{lll}
\hline Glass structure & Interlayer & Amount \\
\hline $4 \mathrm{~mm}$ annealed glass & Trosifol® Clear & 3 \\
$0.76 \mathrm{~mm}$ interlayer & Trosifol ${ }^{\circledR}$ Extra Stiff & 3 \\
$4 \mathrm{~mm}$ annealed glass & SentryGlas & 3 \\
$8 \mathrm{~mm}$ annealed glass & none (monolithic) & 3 \\
$3 \mathrm{~mm}$ annealed glass & & \\
$0.76 \mathrm{~mm}$ interlayer & Trosifol® Extra Stiff & 3 \\
$3 \mathrm{~mm}$ annealed glass & SentryGlas ${ }^{\circledR}$ & 3 \\
\hline
\end{tabular}

For this, vertical glass panes that were linearly supported on four sides were loaded in three steps with different durations according to a load-time correlation (Haldimann, 2008). In the research mentioned above, wind loads were monitored for a long time period to see how wind and maximum wind gusts behave. The analysis showed that a slight wind load acted over several days and rose up to maximum wind gust for just a few seconds. Consequently, wind load scenarios were developed which were close to real conditions. According to the wind scenario for $20^{\circ} \mathrm{C}$, three load steps have to be considered. The loads amount to $25 \%$ over 96 h, $50 \%$ over $10 \mathrm{~min}$ and $100 \%$ of maximum load impact over $3 \mathrm{sec}$.

With the aid of this, the influence of load duration and temperature for each interlayer on the load-bearing behaviour was evaluated. This resulted in correlations between load and deflection as a function of the material behaviour of the interlayer in stiffness and creep. Finally, a comparison of the numerical and experimental results for validating the refined calculation method is provided.

In co-operation with Kuraray Europe $\mathrm{GmbH}$, application-oriented laminated glass specimens with three different interlayers (Trosifol ${ }^{\circledR}$ Clear as a standard-PVB, Trosifol ${ }^{\circledR}$ Extra Stiff as stiff PVB and SentryGlas ${ }^{\circledR}$ as ionoplast) combined with $3 \mathrm{~mm}$ and 4 $\mathrm{mm}$ layers of annealed glass were selected. 


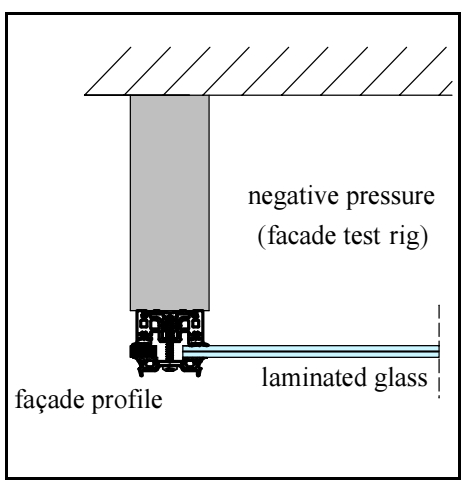

(a)

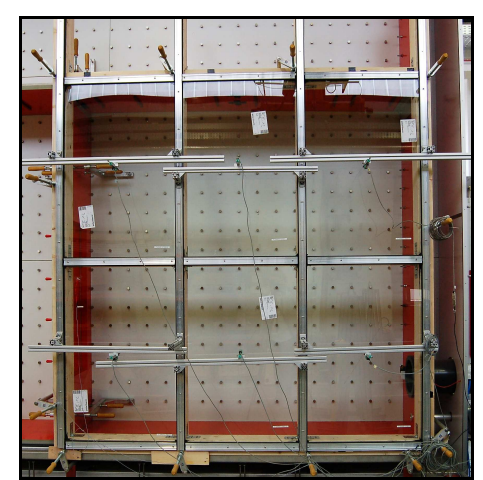

(b)

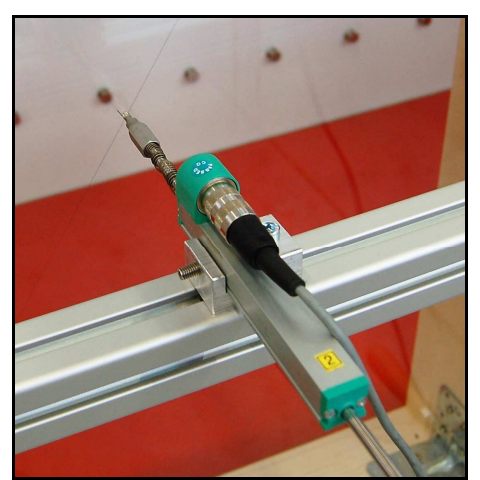

(c)

Fig. 5: (a) Cross section façade test rig (b) Façade test rig assembly (window-sized glazing) (c) Detail inductive displacement sensor

Table 7: Load scenario on the laminated glass specimens

\begin{tabular}{llll}
\hline & & Load $\left[\mathrm{kN} / \mathrm{m}^{2}\right]$ & \\
\hline \multirow{2}{*}{ Load step } & Duration & $\begin{array}{l}\text { Window-sized } \\
\text { glazing }\end{array}$ & $\begin{array}{l}\text { Ceiling-high } \\
\text { glazing }\end{array}$ \\
\hline 1 & $96 \mathrm{~h}$ & 0.5 & 0.25 \\
2 & $10 \mathrm{~min}$ & 1.0 & 0.50 \\
3 & $3 \mathrm{sec}$ & 2.0 & 1.00 \\
\hline
\end{tabular}

Furthermore, monolithic glass panes ( $8 \mathrm{~mm}$ thick) were tested as reference specimens. The specimen dimensions comprised $800 \mathrm{~mm}$ by $1200 \mathrm{~mm}$ as "windowsized glazing" and $1450 \mathrm{~mm}$ by $2800 \mathrm{~mm}$ as "ceiling-high glazing". For statistic reasons, three specimens in each dimension and glass structure were tested. In summary, 36 specimens (Table 6) were examined in the façade test rig.

\section{Test Rig}

For conducting the research in the façade test rig, the glass panes were linearly supported on four sides through a post and mullion substructure (see Fig. 5a and $5 \mathrm{~b}$ ). Negative pressure on the test rig applied a stepwise planar load to the glass panes representing the wind scenario at a temperature of $20^{\circ} \mathrm{C}$. The maximum wind impacts were arrived at by realistic load assumptions and amounted to $2.0 \mathrm{kN} / \mathrm{m}^{2}$ for the windowsized glazings and $1.0 \mathrm{kN} / \mathrm{m}^{2}$ for the ceiling-high glazings. The load scenarios are summarised in Table 7.

For evaluating the load-bearing behaviour and its dependence on time and temperature, the middle deflections (maximum), loads and temperatures were recorded for each glazing during the test. Therefore, an inductive displacement sensor, an inductive pressure sensor and two inductive temperature sensors were installed on each glazing.

\section{Results}

\section{Window-Sized Glazing}

The charts in Fig. 6 illustrate the experimentally (solid line) and numerically determined (dashed line) deflections $u$ for the glass structure 44.2 (4 glass $2 \times 0.38$ $=0.76$ interlayer 4 glass $)$ over time for load step $1(0.5$ $\mathrm{kN} / \mathrm{m}^{2}$ ). For examining the short-term and long-term load-bearing behaviour, the chart is scaled in two periods from 0 to $180 \mathrm{~min}$ (see Fig. 6a) and continues from 3 to 96 hours (see Fig. 6b). During the tests, the temperature ranged between $23^{\circ} \mathrm{C}$ and $28^{\circ} \mathrm{C}$ due to changing climatic conditions in the hall. Therefore, the measured temperatures were implemented in the finite-element model by modifying the shear modulus $G(t, T)$. The material properties of stiff PVB were taken from the Prony-series in (Z-70.3-236) and for the ionoplast from table values that were evaluated in terms of time and temperature (KDT, 2016; Bennison et al., 2001). In contrast, for standard-PVB no shear coupling was assumed according to (DIN 18008). However, the numerical graphs show multiple steps. This resulted in the numerical evaluation of deflections in following time steps: $3 \mathrm{~s}, 30 \mathrm{~s}, 1$ min, $5 \mathrm{~min}, 30 \mathrm{~min}, 1 \mathrm{~h}, 3 \mathrm{~h}, 24 \mathrm{~h}$ and $96 \mathrm{~h}$.

Immediately after load application, the deflections of the glass panes with standard-PVB were twice as high as the amount of those with stiff PVB and ionoplast (see Fig. 6a). This was caused by the lower stiffness of standard-PVB. The numerically determined deflections without shear coupling were once again higher compared to the experimental ones. In conclusion, standard-PVB exhibits shear coupling that leads to a reduction of deflections as well. However, this shear coupling is not allowed to be considered in accordance with the regulations set in (DIN 18008). The viscoelastic deformations (creep) over time have not been included. Time-dependent creep causes a constant increase of deflection of the standard and stiff PVB of the interlayers. The numerical model with the assumptions for the shear stiffness of stiff PVB showed good agreement in comparison with the real load-bearing behaviour. The deflections with ionoplast remained almost constant over the whole load duration. There were no apparent creep influences. This confirmed the high stiffness of the ionoplast interlayer and led to a nearly full shear coupling of the glass panes. 


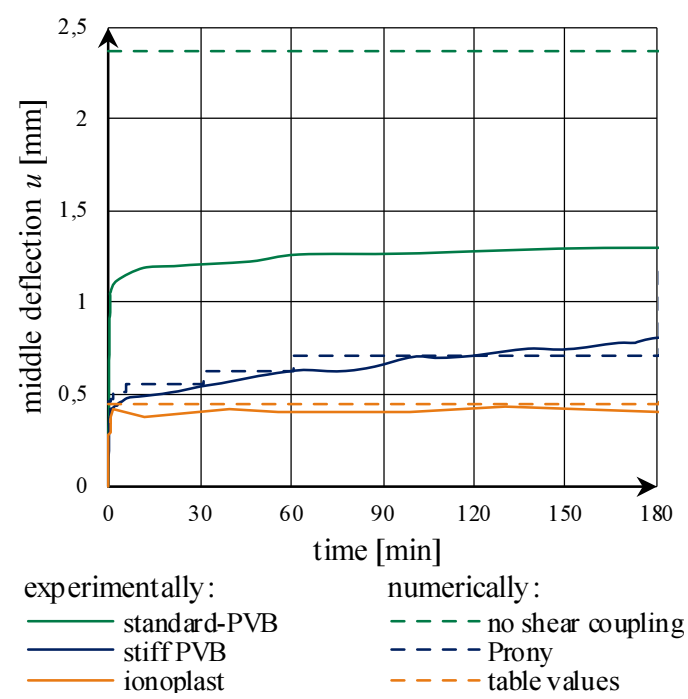

(a)

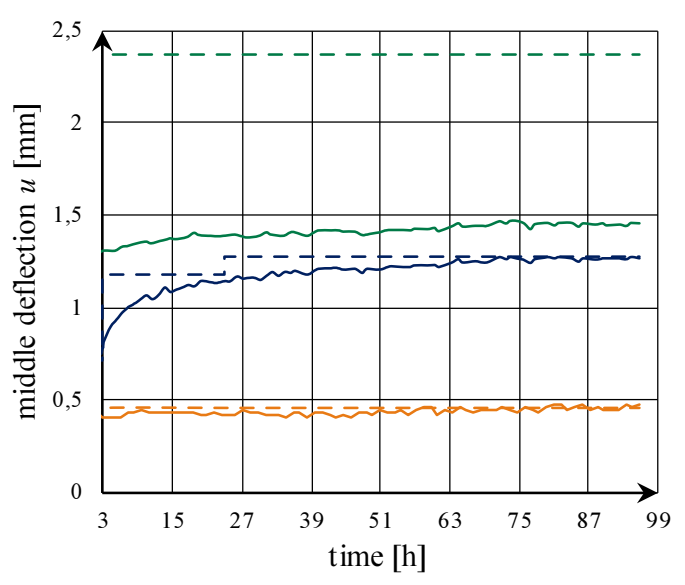

(b)

Fig. 6: Time-middle deflection charts: (a) 0 to 180 minutes (b) 3 to 96 h (load step $1-0.5 \mathrm{kN} / \mathrm{m}^{2}, 44.2$ window-sized glazing)

Table 8: Comparison of numerical and experimental results (44.2 window-sized glazing, deviation in brackets) Deflection $u[\mathrm{~mm}]$

Stiff PVB Ionoplast

\begin{tabular}{lllll} 
Load step & Numerical & Experimental & Numerical & Experimental \\
\hline 1 & $1.28(1 \%)$ & 1.27 & $0.46(2 \%)$ & 0.47 \\
2 & $1.74(1 \%)$ & 1.76 & $0.88(0 \%)$ & 0.88 \\
3 & $2.51(5 \%)$ & 2.64 & $1.72(0 \%)$ & 1.72 \\
\hline
\end{tabular}

Moreover, the numerical model matched the realistic load-bearing behaviour in good agreement for the ionoplast. The small discrepancies that occurred between the numerical and experimental deflections were due to the fact that the supports were modelled as linear supports instead of detailed clamping. Additionally, inaccuracies in measuring the glass structures might also have played a role.

The second chart in Fig. $6 \mathrm{~b}$ shows the long-term behaviour. The deflections with stiff PVB (glass transition temperature of $40^{\circ} \mathrm{C}$ ) got closer to those with standard-PVB (glass transition temperature of $15^{\circ} \mathrm{C}$ to $20^{\circ} \mathrm{C}$ ). Even the temperature remained below $30^{\circ} \mathrm{C}$ during the tests. The stiff PVB at an average temperature of $27^{\circ} \mathrm{C}$ and under continuous loading developed notable creep behaviour. Preliminary examinations have shown, that lower temperatures led to reduced creep of stiff PVB. This behaviour could be numerically modelled with customised shear moduli in good agreement.

At the end of load step 1, the deflections with standard-PVB were the highest. The creep behaviour of stiff $\mathrm{PVB}$ at a temperature of $27^{\circ} \mathrm{C}$ led to deflections close to those of standard-PVB. In contrast, the deflections with ionoplast remained almost constant over the whole load duration. This verifies constant high stiffness even under long-term loading. The end deflections were about one third of those with standard-PVB.

In summary, the experimental results, including the effects of creep and constant loading, could be calculated with the numerical model. The corresponding results showed that the numerical model generates realistic load-bearing behaviour by using the shear moduli that are dependent on both time and temperature.

For validating the approach of pre-deformation in the refined calculation method, the experimental results were compared with the numerical ones in Table 8.

The maximum difference amounted to $5 \%$. This represents good agreement. Consequently, it validates the refined calculation method that takes account of the resulting stresses and deflections from the previous load steps by using the approach of pre-deformation. Furthermore, the load-bearing behaviour can be realistically modelled by using the shear moduli that are dependent on time and temperature.

Hereafter, for validating the model in other dimensions the results for the ceiling-high glazings tested will be given. 


\section{Ceiling-High Glazing}

The graphs in Fig. 7 depict the deflections $u$ over time of the ceiling-high glazings as has been done in the previous chapter. Analogous to window-sized glazings, the deflections of the glass panes with standard-PVB and less stiffness were higher directly after applying the load than the ones with stiff interlayers. Nevertheless, even standard-PVB exhibited noteworthy shear coupling. The value of no shear coupling in the calculation for standard-PVB amounted to $10.71 \mathrm{~mm}$ and exceeded the scale of the chart. Therefore, it is not displayed. The calculations with no shear action (conservative calculation according DIN 18008) strongly mismatch the realistic load bearing behaviour. Creep influences of stiff PVB led to a simultaneous load-bearing behaviour compared to window-sized glazings. Due to the constantly high stiffness of the ionoplast interlayer, the deflections remained constant and almost no timedependent creep occurred. This led to an almost full shear coupling. The results showed good agreement in comparison with the numerical calculations.

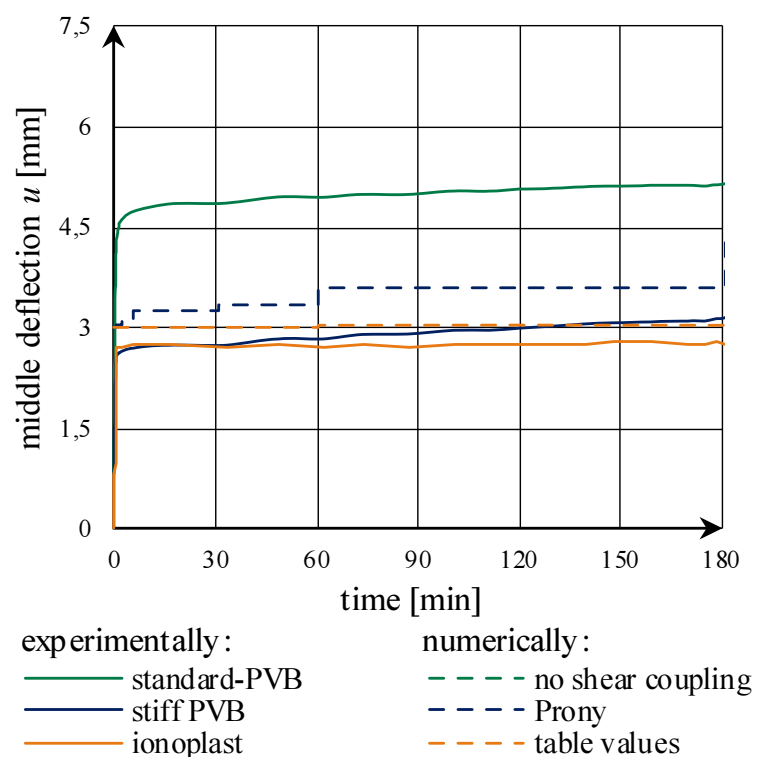

(a)
At the end of load step 1, the deflections with standard-PVB were the highest. The creep behaviour of stiff PVB resulted in end deflections close to those of standard-PVB. Unfortunately, the shear coupling that occurred with standard-PVB cannot be taken into account, according to (DIN 18008). The deflections with ionoplast remained nearly constant due to almost no creep. In total, they amounted to half of those with standard-PVB. The numerical model slightly overestimated the experimental deflections but still led to good agreement.

The experimental results end the end of each load step are compared with the numerical ones in Table 9. The results show good agreement and validate the approach of pre-deformation in the refined calculation method for ceiling-high glazings as well. The size effect leads to slightly higher discrepancies (maximum variance $14 \%$ ) compared to window-sized glazings. However, the numerical results are still safe. Consequently, the refined calculation method can be used to describe the load-bearing behaviour of laminated glass without any unsafe assumptions.

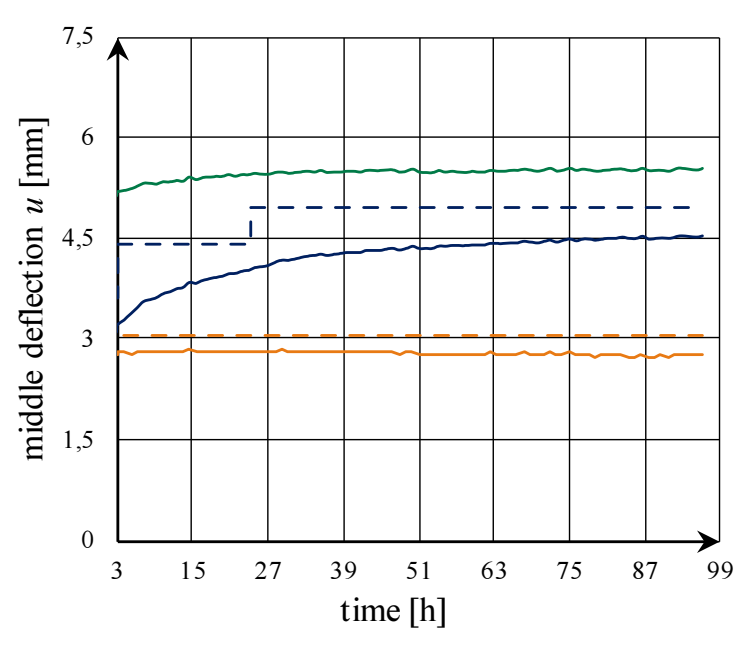

(b)

Fig. 7: Time-middle deflection charts (a) 0 to $180 \mathrm{~min}$ (b) 3 to $96 \mathrm{~h}$ (load step 1-0.5 kN/m², 44.2 ceiling-high glazing)

Table 9: Comparison of numeric and experimental results (44.2 ceiling-high glazing, deviation in brackets)

\begin{tabular}{|c|c|c|c|c|}
\hline \multirow[b]{3}{*}{ Load step } & \multicolumn{4}{|c|}{ Deflection $\mathrm{u}[\mathrm{mm}]$} \\
\hline & \multicolumn{2}{|l|}{ Stiff PVB } & \multicolumn{2}{|l|}{ ionoplast } \\
\hline & Numerical & Experimental & Numerical & Experimental \\
\hline 1 & $4.95(9 \%)$ & 4.54 & $3.04(9 \%)$ & 2.80 \\
\hline 2 & $7.58(8 \%)$ & 6.99 & $5.79(7 \%)$ & 5.39 \\
\hline 3 & $12.18(14 \%)$ & 10.68 & $10.71(6 \%)$ & 10.08 \\
\hline
\end{tabular}




\section{Conclusion}

The examination of load-bearing behaviour with different interlayers in laminated glass verified the refined calculation method and the numerical model assumptions (shear moduli for stiff interlayers and boundary conditions). Standard-PVB exhibited the lowest stiffness caused by the lowest glass transition temperature. Stiff PVB with modified chemical compositions (lower plasticiser content) showed a higher stiffness. Nevertheless, stiff PVB exhibits creep behaviour under long-term loadings and $20^{\circ} \mathrm{C}$ to $30^{\circ} \mathrm{C}$, an aspect that should not be neglected. Those creep deformations increase at higher temperatures, whereas ionoplast showed constant stiffness over time, independent of the temperature - at least for the temperature range that was examined. According to the stiff behaviour, ionoplast can be used for a larger application range in glass constructions, where shear coupling is advantageous.

In summary, the investigations led to a validated, refined model that reproduced the load-bearing behaviour of laminated glass close to reality by taking precise shear moduli for the interlayer into account. In the model, interlayer properties of approvals can be applied as well as values that are dependent on time and temperature. This approach includes creep effects by using the specific shear moduli, which are dependent on time and temperature and combines the loads with the aid of the concept of pre-deformation. All in all, it is a full geometric non-linear calculation method for modelling the load-bearing behaviour of laminated glass in several dimensions as well as glass structures close to reality. This leads to an economic glass design.

In the following chapter, an extended parametric study will be presented that uses the refined calculation method to reduce the self-weight of the construction by combining thin glass panes with stiff interlayers.

\section{Parametric Study}

The objective of the parametric study was to quantify the potential of self-weight reduction by using a combination of thin glass panes and stiff interlayers compared to standard-PVB in laminated glass of insulated glass units. The refined calculation method was used for the parametric study on symmetric doubleglazed insulated glass units with a space of $16 \mathrm{~mm}$ between laminated glass panes in different dimensions (span $a x$ span $b$ ) and glass structures. The inner and outer glass panes consisted of layers of symmetrically laminated glass of $2 \mathrm{~mm}$ to $4 \mathrm{~mm}(2 / 2$ to $4 / 4)$ and an interlayer of standard-PVB, stiff PVB or ionoplast in a thickness of $0.76 \mathrm{~mm}$. The glazings were evaluated for dimensions in the range of $1.0 \mathrm{~m}$ to $4.0 \mathrm{~m}$ for each span. The considered glass structures are summarised in Table 10.

With this, the maximum possible dimensions under equivalent load conditions were evaluated according to (DIN 18008).

Loads such as climatic loads and wind loads were applied to the glazing. Climatic loads, however, have a high load range that functions as the stiffness of the glass panes in insulated glass units. Therefore, climatic loads differ depending on factors like air space between the panes, glass structure, glazing dimensions and geometry.

Table 10: Glass structures and dimensions considered in parametric study

\begin{tabular}{llll}
\hline $\begin{array}{l}\text { glass structure } \\
{[\mathrm{mm}]}\end{array}$ & interlayer & span $a$ & span $b$ \\
\hline $2-0,76-2$ & standard-PVB & $1.0 \mathrm{~m}$ to $4.0 \mathrm{~m}$ & $1.0 \mathrm{~m}$ to $4.0 \mathrm{~m}$ \\
16 spacer & stiff PVB & & \\
$2-0,76-2$ & ionoplast & & \\
$3-0,76-3$ & standard-PVB & $1.0 \mathrm{~m}$ to $4.0 \mathrm{~m}$ & $1.0 \mathrm{~m}$ to $4.0 \mathrm{~m}$ \\
16 spacer & stiff PVB & & \\
$3-0,76-3$ & ionoplast & & \\
$4-0,76-4$ & standard-PVB & $1.0 \mathrm{~m}$ to $4.0 \mathrm{~m}$ & $1.0 \mathrm{~m}$ to $4.0 \mathrm{~m}$ \\
16 spacer & stiff PVB & & \\
$4-0,76-4$ & ionoplast & & \\
\hline
\end{tabular}

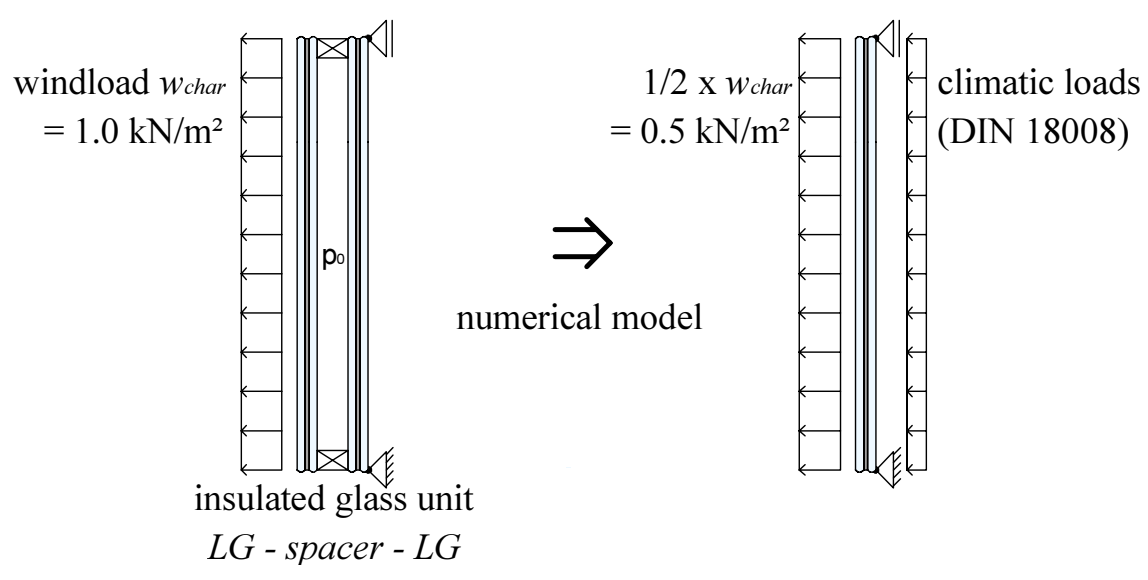

Fig. 8: Boundary conditions and reduced static system 
For the parametric study, climatic loads were determined by the regulations of (DIN 18008) for climatic impacts. In addition, a characteristic wind load for a wide range of possible application areas of $1.0 \mathrm{kN} / \mathrm{m}^{2}$ was applied to the glazing. The conditions are summarised in Fig. 8.

The design was performed according to the regulations in (DIN 18008). Hence, the elastic shear modulus values for wind loads were applied according to Table 1 to the different interlayers. For climatic loads both limit conditions, no and full shear coupling, were considered according to (DIN 18008). Additionally, the load history was considered in the order of loading climatic loads (long duration) and windload (short duration). In order to shorten the calculation time, the model was used on only one glass pane of the insulated glass unit.

The graphs in Fig. 9 depict the borderlines that still fulfil the limit conditions of the SLS with a limitation of deflection 1/100 times the minor span (DIN 18008). In total, the chart displays the allowable dimensions for each glass structure under the load conditions seen in Fig. 8. Both axes were evaluated from 1.0 to $4.0 \mathrm{~m}$ in steps of $0.1 \mathrm{~m}$. In the parametric study, the maximum design stress of ULS was not decisive in any case. The common limit dimensions for annealed glass production is displayed with the borderline at $3.2 \mathrm{~m}$. The glass structure 2/2 $162 / 2$ with standard-PVB did not meet the limit conditions in the evaluated dimensions and is therefore not depicted in the chart. In summary, the loadbearing performance differences can be determined depending on the glass structure and glazing dimensions.

Comparing the glass structures illustrates the potential of self-weight reduction by defining possible glazing dimensions. For instance, the dimensions $1.4 \mathrm{~m}$ by $1.6 \mathrm{~m}$ (ratio $1: 1.33$ ) with the glass structure 4/4 16 4/4 and standard-PVB met the limit condition with a ratio of $99 \%$. The same glazing dimensions are also realisable with thinner laminated glass $3 / 3$ by using stiff PVB or an ionoplast interlayer and taking shear coupling into account in the calculation. Even larger glazings of up to $1.6 \mathrm{~m}$ by $2.2 \mathrm{~m}$ (ratio $1: 1.38$ ) with the glass structure $3 / 3$ $163 / 3$ and stiff PVB or ionoplast are possible. On the one hand, this illustrates self-weight reduction by using thinner laminated glass sections of insulated glass units and, on the other hand, it also illustrates possible larger spans while still meeting the design limit conditions (ULS and SLS).

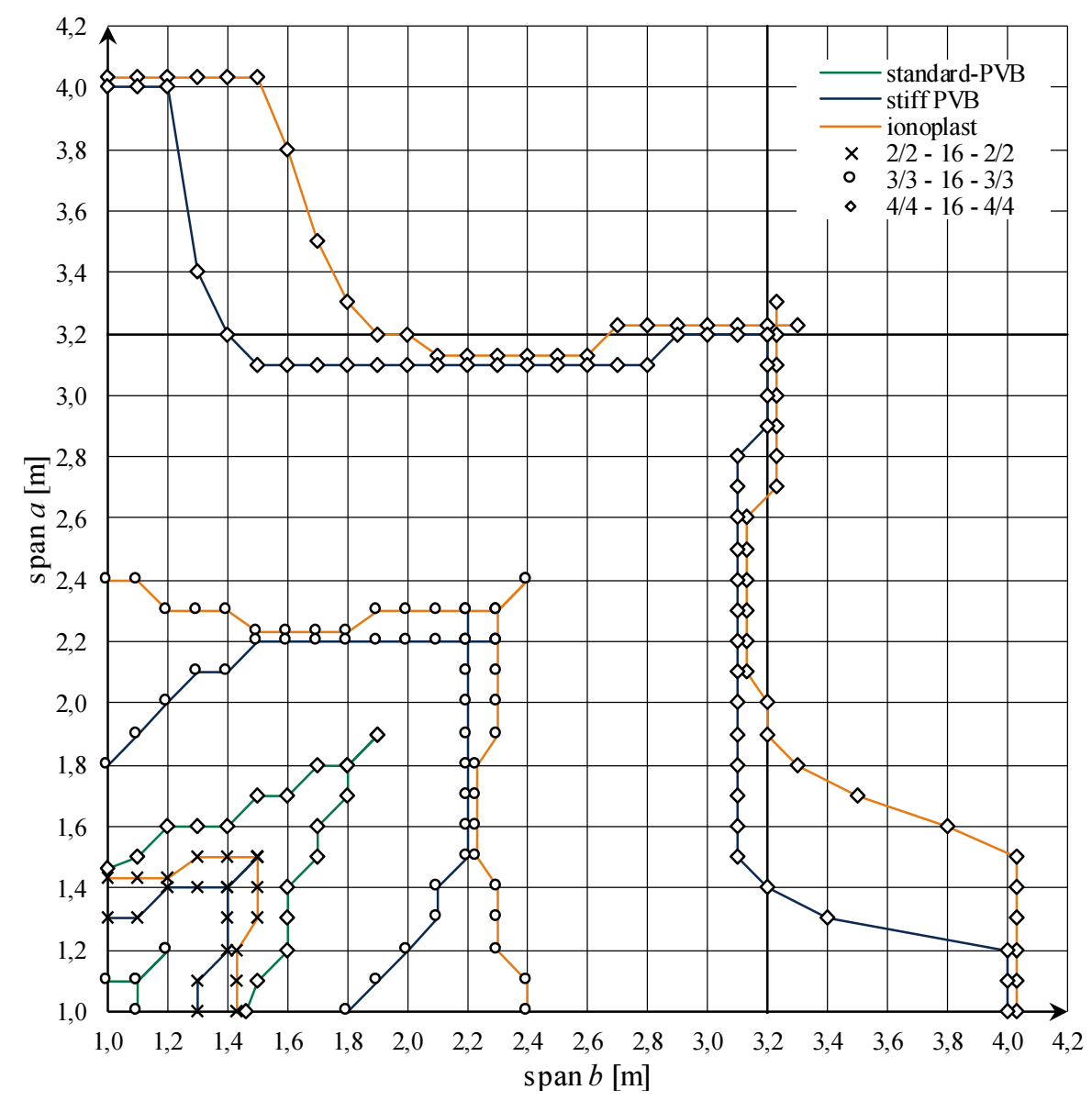

Fig. 9: "Butterfly chart" for describing the borderlines (double-glazed insulated glass unit under climatic loads and wind loads) 

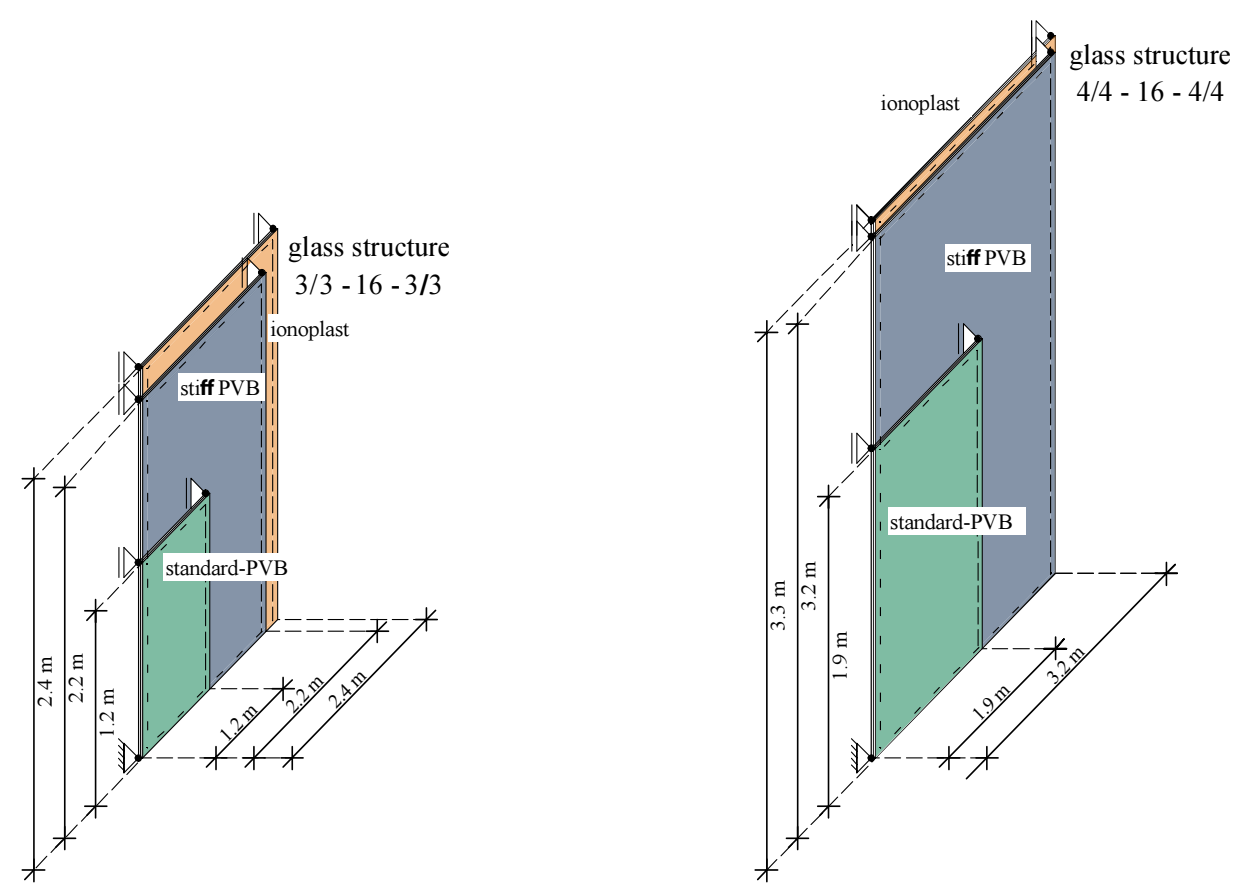

Fig. 10: Maximum glazing dimensions (schematic) for the glass structures of $3 / 3$ 16 3/3 and 4/4 16 4/4 under equivalent load conditions

A comparison between the borderlines of glass structures with stiff PVB and ionoplast exhibits small differences in glazing dimensions. The higher stiffness of the ionoplast led to slightly larger dimensions compared to stiff PVB in similar glass structures.

Due to a stronger impact of membrane effects and less limitation of deflection in quadratic glazings, larger spans are possible. Dependent on the dimension ratio, the load transfer shifted to one direction. Therefore, only smaller spans through stronger limitation of deflection $(1 / 100)$ met the serviceability limit state. When the load transfer shifts to an almost completely uniaxial direction at small spans such as $1.0 \mathrm{~m}$, the second span will rise to the maximum of $4.0 \mathrm{~m}$.

To compare the differences in performance of the evaluated interlayers, the maximum dimensions are schematically shown in Fig. 10. The maximum dimensions with stiff PVB and a glass structure $3 / 316$ $3 / 3$ reached $2.2 \mathrm{~m}$ by $2.2 \mathrm{~m}$ compared to ionoplast $2.4 \mathrm{~m}$ by $2.4 \mathrm{~m}$ through higher stiffness. In contrast, standardPVB showed lower performance with no shear coupling in calculation. This led to maximum dimensions of $1.2 \mathrm{~m}$ by $1.2 \mathrm{~m}$ with the same glass structure. Simultaneously, the dimensions with the glass structure $4 / 4164 / 4$ were $3.2 \mathrm{~m}$ by $3.2 \mathrm{~m}$ (stiff PVB) and $3.2 \mathrm{~m}$ by $3.3 \mathrm{~m}$ (ionoplast) compared to $1.9 \mathrm{~m}$ by $1.9 \mathrm{~m}$ using standard-PVB.

\section{Conclusion}

In conclusion, the application of stiff PVB and ionoplast interlayers led to larger glass designs by taking shear coupling into account compared to standard-PVB without shear coupling. The aim of self-weight reduction in glass panes by using stiff interlayers can be attained. Thus, the parametric study serves as an indicator for new possibilities in the design of insulated glass units. Additionally, it can be used for a rough approximation of the potential of glazing with different interlayers.

\section{Summary}

The paper introduced a complex, refined calculation method for laminated glass including interlayer property assumptions for realistic modelling of load-bearing behaviour. With the approach of pre-deformation and the application of shear moduli that are dependent on time and temperature, a refined full geometric non-linear calculation method for combined loads was developed.

In total, 36 specimens of laminated glass in two dimensions and numerous glass structures were tested in three load steps to validate the numerical model. Additionally, the performance differences of the interlayers with standard-PVB and stiff PVB and ionoplast interlayers were investigated and discussed. Even standard-PVB developed significant shear coupling that cannot be considered according to regulations in (DIN 18008). Hence, the calculations for standard-PVB and no shear coupling were in strong miss agreement with the experimental results. In contrast, the experimental results for stiff PVB and ionoplast interlayer showed good agreement in comparison with numerical calculations and verified the refined calculation method and numerical model. 
This allowed for a parametric study to point out the potential of self-weight reduction by using thin glass panes and stiff interlayers in laminated glass sections of insulated glass units. Using the refined calculation method as well as the potential of the interlayers seems profitable. The results were displayed in a user-oriented "butterfly chart".

In particular, in relatively thin structures the geometric non-linearity significantly affects the resulting stresses and deflections. As a result, new thinner glass constructions can be designed with the aid of the refined model considering shear coupling in geometric nonlinear calculations under combined loads. The article showed that using the complex refined calculation method and considering shear coupling for stiff interlayers allows for realistic modelling, larger laminated glass designs and reduced self-weight. This may lead to more spectacular glass constructions with larger spans and slender substructures.

\section{Acknowledgement}

The research project "Examination of Laminated Glass with Stiff Interlayers" is a collaborative effort of the Institute for building construction, TU Dresden and Kuraray Europe GmbH. The authors gratefully acknowledge the support of Kuraray Europe $\mathrm{GmbH}$ for the provision of test specimens.

\section{Author's Contributions}

Julian Hänig: Developed refined calculation method and numerical model, performed tests and parametric study, evaluated test results, contributed in drafting the article.

Paulina Bukieda: Contributed in analysing and interpreting test results, contributed in drafting the article.

Michael Engelmann: Developed test programme, contributed in drafting the article, reviewed the article.

Ingo Stelzer: Kuraray Contributed specimens, Ingo Stelzer provided information about the interlayers, contributed in the analysis of test results.

Bernhard Weller: Contributed in drafting the article, reviewed the article.

\section{Ethics}

The corresponding author confirms that all of the other authors have read and approved the manuscript and that there are no ethical issues.

\section{References}

Bennison, S.J., C.A. Smith, A. Van Duser and A. Jagota, 2001. Structural performance of laminated safety glass made with "Stiff" Interlayers. In Glass Processing Days 2001, Tamglass Ltd: Tampere.
Bennison, S.J., M.H. Qin and P.S. Davies, 2008. Highperformance laminated glass for structurally efficient glazing. Proceedings of the Innovative Light-Weight Structures and Sustainable Facades, (SSF' 08), Hong Kong, pp: 1-12.

Brenne, W., U. Nickmann and F. Jaschke, 2014. Innovative steel window structures at the Bauhaus Dessau world heritage site: Engineered Transparency, Ernst und Sohn: Düsseldorf, pp: 623-638.

DIN 18008, 2010-2018. 2 Glass in building - Design and construction rules. pp: 1-5.

DIN EN 1990, 2010. Eurocode: Basis of structural design. DIBt: Berlin.

Dlubal Software GmbH, 2016. Program Description RFEM 5: Spatial Models Calculated According to Finite Element Method.

Galuppi, L. and G. Royer-Carfagni, 2012a. Laminated beams with viscoelastic interlayer. Int. J. Solids Structures, 49: 2637-2645. DOI: $10.1016 /$ j.ijsolstr.2012.05.028

Galuppi, L. and G. Royer-Carfagni, 2012b. Effective thickness of laminated glass beams: New expression via a variational approach. Engineering Structures, 38: 53-67. DOI: 10.1016/j.engstruct.2011.12.039

Haldimann, M., A. Luible and M. Overend, 2008. Structural Use of Glass. Zürich, IABSE-AIPC-IVBH.

Hának, T., M. Eliášová, K. Machalická and M. Vokáč, 2017. Determination of PVB interlayer's shear modulus and its effect on normal stress distribution in laminated glass panels. Materials Sci. Eng., 251: 012076. DOI: 10.1088/1757-899X/251/1/012076

Hänig, J., P. Bukieda, M. Engelmann, I. Stelzer and B. Weller, 2018. Leichte Verbundgläser-Potentiale einer Gewichtsreduzierung durch eine gezielte Ausnutzung der Verbundsteifigkeit. Glasbau, 2: 235-251. DOI: $10.1002 /$ cepa.645

Juang, Y., L.J. Lee and K.W. Koelling, 2001. Rheological analysis of polyvinyl Butyral Near the glass transition temperature. Polymer Engineering Sci., 41: 275-292. DOI: 10.1002/pen.10727

KDT, 2016. TROSIFOL Architectural Laminated Glass Interlayers - product portfolio for laminators, Kuraray Division Trosifol.

Kraus, M., M. Botz and G. Siebert, 2018. Structural Design of laminated glass under consideration of the shear coupling according to German. European and US Standards. GlassCon Global Chicago.

Kuntsche, J., M. Schuster, J. Schneider and S. Langer, 2015. Viscoelastic properties of laminated glass interlayers-theory and experiments. Glass Performance Days Tampere, pp: 143-147.

López-Aenlle, M., F. Pelayo, A. Fernández-Canteli and M.A. García Prieto, 2013. The effective-thickness concept in laminated-glass elements under static loading. Engineering Structures, 56: 1092-1102. DOI: $10.1016 / \mathrm{j}$.engstruct.2013.06.018 
Pelayo, F., M.J. Lamela-Rey, M. Muniz-Calvente, M. Lopez-Aenlle and A. Alvarez-Vazquez et al., 2017. Study of the time-temperature-dependent behaviour of PVB: Application to laminated glass elements. Thin-Walled Structures, 119: 324-331.

DOI: $10.1016 /$ j.tws.2017.06.030

PrEN 16612, 2017a. Glass in building - Determination of the load resistance of glass panes by calculation and testing, CEN.

PrEN 16613, 2017b. Glass in building - Laminated glass and laminated safety glass - Determination of interlayer mechanical properties, CEN.

Serafinavičius, T., A. Kuranovas, J.P. Lebet, C. Louter and T. Lenkimas, 2013. Long-term laminated glass four point bending test with PVB, EVA and SG interlayers at different temperatures. Procedia Eng., 57: 996-1004. DOI: 10.1016/j.proeng.2013.04.126
Van Duser, A., A. Jagota and S.J. Bennison, 1999. Analysis of Glass/Polyvinyl Butyral Laminates subjected to Uniform Pressure. J. Eng. Mechanics. DOI: 10.1061/(ASCE)0733-9399(1999)125:4(435)

Z-70.3-170 Allgemeine bauaufsichtliche Zulassung 70.3170. Verbund-Sicherheitsglas aus SentryGlas ${ }^{\circledR}$ SG5000 mit Schubverbund. DIBt: Berlin.

Z-70.3-236 Allgemeine bauaufsichtliche Zulassung 70.3236. Verbund-Sicherheitsglas mit der PVB-Folie TROSIFOL® ES mit Schubverbund. DIBt: Berlin. 